\title{
RECONHECIMENTO DE NÓDULOS POULMONARES UTILIZANDO A TRANSFORMADA DE HOUGH E TEXTURA
}

\author{
Fabio da S. Severiano \\ Doutorando em Modelagem Computacional, UERJ \\ 28625-570, Nova Friburgo, RJ \\ E-mail: fabiosseveriano@hotmail.com \\ João Flavio V. Vasconcelos \\ D.Sc. Engenharia Mecânica \\ E-mail: jflavio@ @iprj.uerj.br \\ Joaquim T. de Assis \\ D.Sc. Engenharia Nuclear \\ E-mail: joaquim@iprj.uerj.br
}

\begin{abstract}
$\underline{\text { RESUMO }}$
A utilização de imagens tomográficas no diagnóstico médico de nódulos pulmonares é um procedimento cada vez mais comum, devido a ser um método não invasivo e por gerar imagens de alta qualidade, permitindo a visualização detalhada de estruturas [1]. Com o desenvolvimento do hardware e das técnicas de processamento de imagens, começaram a surgir sistemas para a detecção assistida por computador (CAD) [2]. Este trabalho, que está em fase de desenvolvimento, tem a finalidade de criar um software que auxilie o profissional médico na detecção e visualização de nódulos pulmonares solitários, utilizando como parâmetros para a busca a geometria dos nódulos, que é elíptica, ovalada, e da análise de textura.

Para isso é utilizada a Transformada de Hough [3], que é capaz de localizar estruturas circulares e elípticas em uma imagem e descritores de textura que indicam as características de uma determinada estrutura em uma imagem [4] [5]. Em pesquisa bibliográfica, não foram encontrados trabalhos que utilizem essas combinações de técnicas com essa mesma finalidade. Para os testes iniciais estão sendo utilizadas imagens com 256 tons de cinza, com dimensões de 512 por 512 pixels. Neste processo serão utilizados quatro passos: a localização dos pulmões, a localização das estruturas candidatas, a eliminação de falsos positivos, criação de banco de dados de estruturas e a visualização tridimensional dos nódulos.

$\mathrm{Na}$ etapa de localização dos pulmões, tem-se como principal componente a diferença de intensidade de tons de cinza. Os pulmões possuem uma coloração bem escura e as estruturas externas possuem um valor de tonalidade bem aproximada ao branco, permitindo a segmentação através da utilização de um limiar de corte e, para esse tipo de imagem, o valor utilizado foi de 127. Preenchendo-se as estruturas internas pulmonares, é possível a eliminação de pequenas faixas escuras que possam existir abaixo ou acima da região pulmonar [2].

A detecção dos candidatos a nódulo, começa com a utilização de um filtro de mediana para a remoção de pixels solitários e então é executado um processo de fechamento morfológico [6], para melhorar a definição das estruturas existentes nos pulmões. A imagem é transformada em bordas através do filtro de Canny [7] e então procura-se as estruturas de forma oval e elíptica através da transformada de Hough [3].

Na etapa corte de falsos positivos, são analisadas as características pertinentes à textura dos candidatos. Primeiramente é calculada a matriz de co-ocorrência da região, que armazena a quantidade de transições entre todas as tonalidades de cinza, de pixels vizinhos, nos ângulos de $0^{\circ}, 45^{\circ}, 90^{\circ}$ e $135^{\circ}$ [4] [5]. Calcula-se então a probabilidade de ocorrência de cada transição da matriz de co-ocorrência e então as seguintes características: Segundo Momento Angular, também conhecido como Energia, serve para identificar o grau de ordenação da região; Entropia, mede o nível de dispersão dos níveis de cinza; Contraste, mede a variação de
\end{abstract}


intensidade entre pares de pixels; Correlação, mede a dependência linear entre um pixel e seus vizinhos; Uniformidade, mede a uniformidade da região; Homogeneidade, mostra se existe similaridade entre os níveis de cinza; e Variância, mede a dispersão dos valores em torno de um valor médio [4] [5].

Os valores obtidos são comparados com os de um banco de dados previamente preenchido, através da técnica do vizinho mais próximo [8], que utiliza a raiz da soma dos quadrados das diferenças entre as $n$ dimensões de um vetor como fator de comparação.

Neste banco é armazenada a análise de texturas de nódulos, de capilares e de áreas sem estruturas.

Por fim o nódulo será visualizado tridimensionalmente através da técnica de visualização de volumes de Marching Cubes [9]. Nesta técnica as fatias de um volume são cercadas por uma grade de células de tamanho pré-definido. Os vértices cortados pela imagem são marcados, e farão parte da isosuperfície final.

Existem 256 possibilidades de cruzamento de vértices, que devem ser catalogados e recuperados após a análise de cada célula tridimensional. O volume é dado pela junção de todas as células e mostrará o contorno tridimensional do objeto.

Palavras-chave: Nódulos pulmonares, CAD, Hough, Analise de textura, Marching Cubes.

\section{Referências}

[1] ABC.MED.BR, 2013. "Tomografia computadorizada". Como é o exame?. Disponível em: <http://www.abc.med.br/p/exames-e-procedimentos/344744/tomografia-computadorizadacomo-e-o-exame.htm>. Acesso em: 26 fev. 2014.

[2] Z. Azimifar, R. Boostani, M. Keshani, F. Tajeripour, "Lung nodule segmentation and recognition using SVM classifier and active contour modeling: A complete intelligent system" , pp 287-300, Elsevier, 2013.

[3] R. O. Duda, P. E. Hart, "Use of the Hough Transformation to Detect Lines and Curves in Pictures", pp. 72-147, ACM, 1972.

[4] S. R. Fernandes, "Caracterização de Imagens de Microtomografia de Raios X Baseada em Descritores de Textura", Tese de Doutorado, UERJ, 2012.

[5] J. P. R do Nascimento, " Análise e Classificação de Imagens Baseadas em Características de Textura Utilizando Matrizes De Co-ocorrência ", Dissertação de Mestrado, UFPR, 2003.

[6] R. C. Gonzalez, R. E Woods, "Digital Image Processing". Reading, Addison-Wesley,1992.

[7] J. Canny, "A computational approach to edge detection. Pattern Analysis and Machine Intelligence", pp 679-698, IEEE Transactions on, 1986.

[8] S. Kelly, N. Roussopoulos, F. Vincent, "Nearest Nighbor Queries", pp 71-79, SIGMOD, New York, 1995.

[9] P. Bourke, "3D Contouring, Marching Cubes, Surface Reconstruction", 1994. 